\title{
Clustering based hybrid approach for facility location problem
}

\author{
Ashish Sharma ${ }^{a^{*}}$, Ashish Sharma ${ }^{b}$ and A. S. Jalal ${ }^{b}$
}

${ }^{a}$ Department of Mathematics, GLA University, $17 \mathrm{~km}$ stone, NH\#2, Mathura (UP), India

${ }^{b}$ Department of Computer Engineering \& Applications, GLA University, $17 \mathrm{~km}$ stone, NH\#2, Mathura (UP), India

\section{H R O N I C L E}

Article history:

Received: July 24, 2017

Received in revised format: $\mathrm{Au}$ gust 6,2017

Accepted: August 25, 2017

Available online:

August 25, 2017

Keywords:

Facility location problem

Fuzzy demand

Region search

Distance based FLP

\section{A B S T R A C T}

\begin{abstract}
The main objective of facility location problem is the utilization of the facility by maximum number of possible customers so that the profit is maximized. For instance, in some services like wireless sensor networks, Wi-Fi, repeaters, etc., where the service area is limited, some specific equipment is installed in such a way that it could be used by maximum number of users. Here, the number of users for a particular facility is optimized with the help of clustering technique. The study develops a model for facility allocation problem. For the solution algorithm, a hybrid approach which is based on clustering and mixed integer linear programming (MILP) is proposed. The proposed method consists of two parts where in the first part, the K- means clustering technique is used and in the second part, for each cluster an MILP technique is implemented so that the facility which yields the maximum profit is obtained. Numerical examples for clustering and without clustering are presented. Analysis shows that due to clustering the average distance between facility and customer is significantly reduced.
\end{abstract}

\section{Introduction}

In some situations like wireless sensor networks, Wi-Fi, repeaters, signals transmission etc. the service area for a facility is limited. In other words, if the customer is in the range of a particular facility then only s/he can avail services. Another observation in day to day life is that customers generally prefer the facilities like automated telling machine (ATM), Petrol pumps, etc. which are near to them. In both the situations we can conclude that the distance between the facility and the customer plays an important role for the utilization of the facility. Thus in the installation of the facility one of the primary objectives is to keep the low distance between the customers and the facility so that the facility would be utilized by a large number of customers which resultantly increases the profit.

After going in the deep discussion with experts and published literatures of the clustering, we think that this objective can be met by using clustering techniques. By clustering we can club the customers which lie in a specific range. In the literature we have found that many authors considered clustering for FLP. Geetha et al. (2009) proposed a solution procedure for the capacitated clustering problem (CCP) by

* Corresponding author. Tel.: +91-5662-250826), Fax: +91-5662-241486

E-mail address: ashishsharma@gla.ac.in (A. Sharma) 
improving k-means clustering algorithm, by setting the priority as a measure which directs the search for better optimization. A new solution framework for Capacitated P-median problem (CPMP) is proposed by Sahraeian and Kaveh (2010). CPMP locates P facilities between the candidate points to satisfy the customer demand. Their approach is hybrid of K-means clustering algorithm. Saiedy et al. (2011) present a modeling of capacitated single allocation hub location problem with two indices.

A review of hierarchical facility location models is presented by Farahani et al. (2014). This review explains the facility layout problem (FLP) in two points of views. First one is based on cost minimization objective and the other one is based on service availability maximization objective. Another review paper on FLP given by Arabani and Farahani (2012) includes multiple dynamics of FLP with mathematical formulations. A review with different solution methods and the latest development for the three different categories of the FLP i.e. bi-objective, multi-objective and multi-attribute problems has provided by Farahani et al. (2010).

Some authors also used the integer programming techniques in order to obtain the best facility. The Capacitated Facility Location Problem (CFLP) is performed by Liao and Guo (2008) using mixed approach based on k-means and genetic algorithms. Kolisch and Dahlmann (2015) consider the dynamic assigning of replicas to the servers in their service based solution. To make more approximate solution Arya et al. (2004) uses the local search heuristic algorithm with k-means. Another type of facility location is Continuous Facility Location problem explored by (Meira \& Miyazawa, 2008). Authors have presented algorithms with new approximation factors for Euclidean distances and squared Euclidean distances using k-means clustering algorithm for the small dimensions.

Many authors used the clustering techniques for the solution of FLP. (Chaves \& Dahlmann, 2010) has proposed the Capacitated Centered Problem. It consists partitioning a collection of ' $n$ ' points into ' $p$ ' disjoint clusters with a noted capability. Wena and Iwamura (2008) considere the facility location problem and vehicle routing problem both simultaneously. In another paper the multi-level un-capacitated facility location problem is considered by (Kaya \& Urek, 2016). They have considered mixed integer linear programming (MILP) as a solution and validated. Shishebori and Ghaderi (2015) consider the combined facility location/network design problem with regard to transportation link disruptions and develops a mixed integer linear programming formulation to model it. An efficient hybrid algorithm based on LP relaxation and variable neighborhood search meta-heuristic is developed in order to solve the mathematical model.

To the best of our knowledge we did not found any work which used the clustering and the MILP for the solution of the FLP. Thus to meet this limitation, in this paper, we first defined the mathematical model of the FLP which contains the objective functions and the constraints based on capacity and demand. For the solution of the FLP we used the mixed algorithm of clustering and the MILP. In which in the first step we apply K-means clustering techniques over a set of customers and facilities so that we will get the required number of clusters. Now in each clusters, the possibilities are:

1. Each cluster contains some customers and some facilities.

2. Some clusters contain customers as well as facilities and some clusters contain only customers.

3. Some clusters contain customers as well as facilities and some clusters contain only facility.

Thus in the presence of all such possibilities we prepare an algorithm for the solution. After clustering we apply the MILP on each cluster to get the best facility which provides the maximum profit. Thus by summing up the profit of individual cluster we will get the overall optimum profit. Initially we start this algorithm for 2 clusters and then we gradually increase the clusters. At some stage we will get the maximum profit and if we further increase the clusters then the profit will start decreasing. Thus with the help of this algorithm we can also obtain the number optimum clusters for a particular FLP.

The basic research question we addressed in this paper are; 
(1) Is clustering is helpful to obtain the basic objective of minimizing the distance between the customer and facility?

(2) What will be the optimum number of clusters, if number of opening of facilities is not restricted?

\section{The proposed method}

\subsection{Notations, Definitions and Properties}

The following notations are used in this paper:

$\mathrm{i}=$ Index of facilities, $1 \leq \mathrm{i} \leq \mathrm{n}$

$\mathrm{j}=$ Index of customers $1 \leq \mathrm{j} \leq \mathrm{m}$

$\left(A_{j}, B_{j}\right)=$ location of the customer $\mathrm{j}, 1 \leq \mathrm{j} \leq \mathrm{m}$.

$\left(A_{i}, B_{i}\right)=$ location of the facility $\mathrm{i}, 1 \leq \mathrm{i} \leq \mathrm{n}$

$D_{j}=$ demand of customer $\mathrm{j}$

$r_{j}=$ Price charged to client $\mathrm{j}$, i.e. per Unit

$s_{i}=$ Capacity of facility i

$c_{i}=$ The Opening and operating facility fixed cost of a facility $\mathrm{i}$

$V_{i}=$ The Operating cost, i.e. a real number and unit variable of the facility $\mathrm{i}$

$x_{i}=$ Decision variable, i.e. binary, the value 1 , if facility $i$ is open, and zero otherwise

$y_{i j}=$ The supplied quantity to from $\mathrm{i}$ to $\mathrm{j}$

$t_{i j}=$ The cost of transportation from $\mathrm{i}$ to $\mathrm{j}$

We use the following assumptions for the model

1. The capacity, facility cost and the variable cost of the facility are fixed.

2. The demand of the individual customer is fixed.

3. Clustering is based upon the euclidian distance of the customer and the facility.

4. Transportation cost of per unit per unit distance for all customers is same.

\subsection{Modeling formulation}

After finding the Euclidian distance between the facility and the customer we apply k-means algorithm for the formation of clusters so that customers and the facilities are divided into different clusters. To gain the maximum profit we have to identify the facility location point for which the profit is maximum that can be done by profit function that we have defined in our next section. The facility for which the objective function is maximum, is achieved by mixed integer linear programming. This point becomes the facility location point in the cluster. In this problem, our main aim is to maximize the profit function in the presence of the constraint related to supply, capacity, demand and distance. In the objective function, we subtract the unit operating cost and the unit transportation cost from the unit price charged to customer, so that we get the unit revenue earned and then we will multiply it by the quantity supplied so that, we get the total revenue earned. Now, for the profit function we subtract the operating cost of the facility from the total revenue earned. Thus, the objective function is

$$
\max \left\{\sum_{i=1}^{n} \sum_{j=1}^{m}\left[\left(r_{j}-V_{i}-t_{i j}\right) y_{i j}\right]-\sum_{i=1}^{n} c_{i} x_{i}\right\}
$$

We restricted that the demand for a particular customer must be greater than or equals to the total supply from all the facilities. In notations it is defined as 
Similarly, the capacity for a particular facility must be greater than or equal to the supply. In terms of mathematical inequalities it is defined as

$$
\sum_{j=1}^{m} y_{i j} \leq s_{i} x_{i}, i=1,2, \ldots . n
$$

Thus the final facility allocation problem will be

$$
\max \left\{\sum_{i=1}^{n} \sum_{j=1}^{m}\left[\left(r_{j}-V_{i}-t_{i j}\right) y_{i j}\right]-\sum_{i=1}^{n} c_{i} x_{i}\right\}
$$

subject to

$$
\begin{aligned}
& \sum_{j=1}^{m} y_{i j} \leq D_{j}, j=1,2, \ldots . m \\
& \sum_{j=1}^{m} y_{i j} \leq s_{i} x_{i}, \quad i=1,2, \ldots . n \\
& x_{i} \in\{0,1\}, i=1,2, \ldots . n \\
& y_{i j} \geq 0, i=1,2, \ldots . . n ; j=1,2, \ldots . . m
\end{aligned}
$$

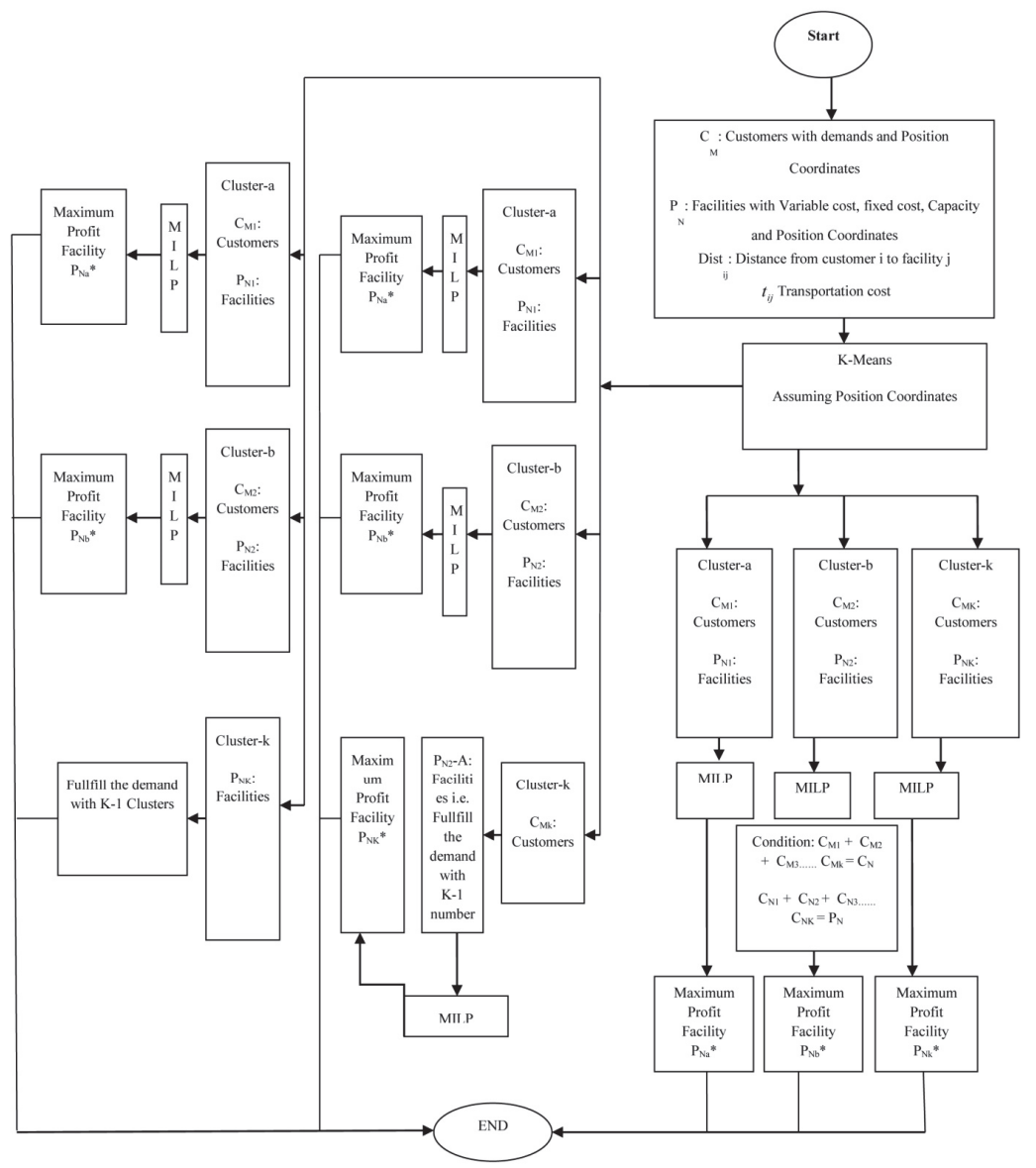

Fig. 1. shoes the flow chart of the proposed approach for FLP 


\section{Numerical Examples}

We now present the numerical examples to illustrate the solution procedure.

Example1: Table 1 shows the values of the fixed cost, capacity and variable cost for all the 10 locations (P1 to P10). Table 2 shows the demand for all the 50 customers (C1 to C50).Transportation Cost 200/unit/unit distance and Price charged to client j is 150000 per Unit. We have taken the data sets of (Lin, 2014).

Table 1

Fixed Cost $\left(\times 10^{7}\right)$, Capacity and Variable Cost $\left(\times 10^{6}\right)$

\begin{tabular}{ccccccccccc}
\hline Locations & P1 & P2 & P3 & P4 & P5 & P6 & P7 & P8 & P9 & P10 \\
\hline Fixed cost & 4.385 & 1.056 & 5.312 & 1.018 & 2.930 & 1.1372 & 4.455 & 4.412 & 4.185 & 5.16 \\
Capacity & 4000 & 1500 & 1800 & 1300 & 1000 & 3400 & 3700 & 1800 & 4000 & 4200 \\
Variable cost & 1.0 & 1.1 & 1.1 & 1.1 & 1.1 & 1.0 & 1.0 & 1.1 & 1.0 & 1.0 \\
\hline
\end{tabular}

Table 2

Demand for 50 customers (C1 to $\mathrm{C} 50)$

\begin{tabular}{|c|c|c|c|c|c|c|c|c|c|c|}
\hline Customers & $\mathrm{C} 1$ & $\mathrm{C} 2$ & $\mathrm{C} 3$ & $\mathrm{C} 4$ & $\mathrm{C} 5$ & $\mathrm{C} 6$ & $\mathrm{C} 7$ & $\mathrm{C} 8$ & C9 & $\mathrm{C} 10$ \\
\hline Demand & 12 & 14 & 121 & 12 & 134 & 5 & 114 & 21 & 132 & 14 \\
\hline Customers & C11 & $\mathrm{C} 12$ & $\mathrm{C} 13$ & $\mathrm{C} 14$ & $\mathrm{C} 15$ & $\mathrm{C} 16$ & $\mathrm{C} 17$ & $\mathrm{C} 18$ & $\mathrm{C} 19$ & $\mathrm{C} 20$ \\
\hline Demand & 15 & 14 & 21 & 32 & 7 & 15 & 14 & 21 & 32 & 11 \\
\hline Customers & $\mathrm{C} 21$ & $\mathrm{C} 22$ & $\mathrm{C} 23$ & $\mathrm{C} 24$ & $\mathrm{C} 25$ & $\mathrm{C} 26$ & $\mathrm{C} 27$ & $\mathrm{C} 28$ & $\mathrm{C} 29$ & $\mathrm{C} 30$ \\
\hline Demand & 15 & 14 & 21 & 32 & 74 & 15 & 24 & 21 & 22 & 64 \\
\hline Customers & C31 & C32 & C33 & C34 & C35 & $\mathrm{C} 36$ & C37 & C38 & C39 & $\mathrm{C} 40$ \\
\hline Demand & 24 & 15 & 11 & 22 & 12 & 14 & 25 & 4 & 21 & 32 \\
\hline Customers & $\mathrm{C} 41$ & $\mathrm{C} 42$ & C43 & C44 & C45 & C46 & C47 & C48 & C49 & C50 \\
\hline Demand & 72 & 15 & 14 & 21 & 7 & 65 & 54 & 21 & 32 & 18 \\
\hline
\end{tabular}

Total Customer $=50$, Total Demand $=2062$ units

Results: Table 3(a) to Table 3 (d) shows the result of the numerical example 1 for the cases without clustering and clustering for number of clusters $=2-5$ when facility and variable cost are different.

Table 3(a)

Number of clusters $=2$

\begin{tabular}{|c|c|c|c|c|}
\hline \multirow[b]{2}{*}{ Locations } & \multicolumn{2}{|c|}{ Without Clustering } & \multicolumn{2}{|c|}{ With Clustering } \\
\hline & $\mathrm{P} 1$ & P6 & $\mathrm{P} 10$ & P6 \\
\hline Total distance of a customer from a particular facility & 43.31 & 39.11 & 22.69 & 21.18 \\
\hline Total distance between all customer $\&$ facilities & \multicolumn{2}{|c|}{82.42} & \multicolumn{2}{|c|}{43.87} \\
\hline No. of customers whose demand was satisfied & 20 & 30 & 26 & 24 \\
\hline Average Customer Distance from a particular facility & 2.17 & 1.31 & 0.88 & 0.89 \\
\hline Profit for each cluster & \multicolumn{2}{|c|}{$\ldots \ldots \ldots \ldots \ldots$} & 36220030 & 47025410 \\
\hline Total Profit & & & \multicolumn{2}{|c|}{83245440} \\
\hline
\end{tabular}

Table 3(b)

Number of clusters $=3$

\begin{tabular}{|c|c|c|c|c|c|c|}
\hline \multirow[b]{2}{*}{ Locations } & \multicolumn{3}{|c|}{ Without Clustering } & \multicolumn{3}{|c|}{ With Clustering } \\
\hline & P1 & P6 & P8 & P10 & P6 & P4 \\
\hline Total distance of a customer from a facility & 43.53 & 36.93 & 3.65 & 19.29 & 28.38 & 25.97 \\
\hline Total distance between all customer $\&$ facilities & \multicolumn{3}{|c|}{84.11} & \multicolumn{3}{|c|}{73.64} \\
\hline No. of customers whose demand was satisfied & 19 & 29 & 2 & 16 & 21 & 13 \\
\hline Average Customer Distance from facility & 2.29 & 1.27 & 1.82 & 1.21 & 1.35 & 1.99 \\
\hline Profit for each cluster & \multicolumn{3}{|c|}{$\ldots \ldots \ldots \ldots \ldots \ldots$} & 27689400 & 37980460 & $1.9 \mathrm{E}+07$ \\
\hline Total Profit & & 6548073 & & \multicolumn{3}{|c|}{84235350} \\
\hline
\end{tabular}

Table 3(c)

Number of clusters $=4$

\begin{tabular}{|c|c|c|c|c|c|c|c|c|}
\hline Locations & P1 & P3 & P6 & P8 & P7 & P8 & P1 & P6 \\
\hline Total distance of a customer from a facility & 43.05 & 8.55 & 34.68 & 3.65 & 30.74 & 19.93 & 56.17 & 18.75 \\
\hline Total distance between all customer \& facilities & \multicolumn{4}{|c|}{89.96} & \multicolumn{4}{|c|}{125.59} \\
\hline No. of customers whose demand was satisfied & 19 & 2 & 27 & 2 & 15 & 12 & 1 & 22 \\
\hline Average Customer Distance from facility & 2.27 & 4.2 & 1.29 & 1.83 & 2.05 & 1.66 & 56.17 & 0.853 \\
\hline Profit for each cluster & & & & & 23842850 & 21986210 & 741830 & 34446350 \\
\hline Total Profit & \multicolumn{4}{|c|}{86897460} & \multicolumn{4}{|c|}{81017240} \\
\hline
\end{tabular}


Table 3(d)

Number of clusters $=5$

\begin{tabular}{|c|c|c|c|c|c|c|c|c|c|c|}
\hline Locations & $\mathrm{P} 1$ & P3 & P4 & P6 & P8 & P4 & $\mathrm{P} 10$ & P3 & $\mathrm{P} 1$ & P7 \\
\hline $\begin{array}{l}\text { Total distance of a cus- } \\
\text { tomer from a facility }\end{array}$ & 42.68 & 22.88 & 34.82 & 3.65 & 0 & 18.75 & 12.69 & 10.13 & 56.17 & 28.83 \\
\hline $\begin{array}{l}\text { Total distance between } \\
\text { all customer \& facilities }\end{array}$ & \multicolumn{5}{|c|}{104.03} & \multicolumn{5}{|c|}{126.57} \\
\hline $\begin{array}{l}\text { No. of customers whose } \\
\text { demand was satisfied }\end{array}$ & 17 & 2 & 28 & 2 & 0 & 22 & 9 & 5 & 2 & 12 \\
\hline $\begin{array}{l}\text { Average Customer Dis- } \\
\text { tance from facility }\end{array}$ & 2.52 & 11.44 & 1.25 & 1.83 & 0 & 0.85 & 1.41 & 2.03 & 28.09 & 2.4 \\
\hline Profit for each cluster & \multirow{2}{*}{\multicolumn{5}{|c|}{ 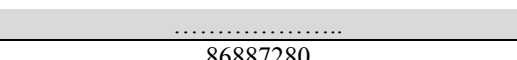 }} & 34446370 & 17467210 & 7959210 & 741830 & 20187890 \\
\hline Total Profit & & & & & & \multicolumn{5}{|c|}{80802510} \\
\hline
\end{tabular}

Thus the maximum profit $8,42,35,350$ and the minimum distance 73.64 units, corresponds to the number of clusters $=3$.

Example 2: Now for the further insights of the model, we consider the case when the variable cost and fixed cost are same for all the facilities. We considered fixed cost $=4,00,000$ and Variable cost $=$ $1,00,000$ for all the locations. All other parameters like demand of customers, transportation cost and the price charged to client $\mathrm{j}$ are same as considered in example 1. Tables 4(a-d) report the result when facility and variable cost are different.

Table 4(a)

Number of clusters $=2$

\begin{tabular}{|c|c|c|c|c|}
\hline \multirow{2}{*}{$\begin{array}{l}\text { Approach } \\
\text { Locations }\end{array}$} & \multicolumn{2}{|c|}{ Without Clustering } & \multicolumn{2}{|c|}{ With Clustering } \\
\hline & P4 & P10 & P10 & P4 \\
\hline Total distance of a customer from a particular facility & 18.2 & 23.82 & 22.69 & 21.18 \\
\hline Total distance between all customer $\&$ facilities & \multicolumn{2}{|c|}{42.02} & \multicolumn{2}{|c|}{43.87} \\
\hline No. of customers whose demand was satisfied & 25 & 25 & 26 & 24 \\
\hline Average Customer Distance from a particular facility & 0.728 & 0.9528 & 0.87269231 & 0.8825 \\
\hline Profit for each cluster & \multicolumn{2}{|c|}{$\ldots \ldots \ldots$} & 38199330 & 37757270 \\
\hline
\end{tabular}

Table 4(b)

Number of clusters $=3$

\begin{tabular}{ccccccc}
\hline Locations & P4 & P6 & P10 & P10 & P6 & P4 \\
\hline Total distance of a customer from a particular facility & 15.42 & 17.76 & 21.52 & 19.29 & 28.38 & 25.97 \\
Total distance between all customer \& facilities & & 54.7 & & & 73.64 & \\
$\quad$ No. of customers whose demand was satisfied & 21 & 9 & 20 & 16 & 21 & 13 \\
Average Customer Distance from a particular facility & 0.74 & 1.98 & 1.08 & 1.21 & 1.36 & 1.99 \\
Profit for each cluster & & $\ldots \ldots \ldots$ & & 28668700 & 29475170 & 18094250 \\
\hline Total Profit & 76012940 & & \multicolumn{7}{c}{76238120} \\
\hline
\end{tabular}

Table 4(c)

Number of clusters $=4$

\begin{tabular}{|c|c|c|c|c|c|c|c|c|}
\hline Locations & P4 & P6 & P7 & $\mathrm{P} 10$ & P7 & P8 & P1 & P6 \\
\hline Total distance of a customer from a particular facility & 12.21 & 15.42 & 17.13 & 19.78 & 30.74 & 19.93 & 56.17 & 18.75 \\
\hline Total distance between all customer $\&$ facilities & \multicolumn{4}{|c|}{64.54} & \multicolumn{4}{|c|}{125.59} \\
\hline No. of customers whose demand was satisfied & 6 & 21 & 8 & 15 & 15 & 12 & 1 & 22 \\
\hline $\begin{array}{l}\text { Average Customer Distance from a particular facility } \\
\text { Profit for each cluster }\end{array}$ & 2.04 & 0.74 & 2.15 & 1.32 & $\begin{array}{c}2.05 \\
23818410\end{array}$ & $\begin{array}{c}1.67 \\
21979330\end{array}$ & $\begin{array}{c}56.17 \\
545680\end{array}$ & $\begin{array}{c}0.86 \\
28346810\end{array}$ \\
\hline Total Profit & & \multicolumn{4}{|c|}{74690230} \\
\hline
\end{tabular}

From the Table 4(a) to Table 4 (d) we can observe that in case of clustering, when the number of cluster are 2 , the total distance travelled by customers is less as compare to without clustering, which results the reduced transportation cost hence the more profit. Now if we further increase the number of clusters the total distance in case of clustering starts increasing, which results the more transportation 
cost and less profit. Thus from Table 4, for the three clusters we will get the maximum profit Rs. $7,62,381,20$ and the minimum distance 73.64 units. This shows that the clustering to a certain limit is useful as it decrease the distance between the facility and the customers. The proposed algorithm also provides the number of optimum clusters so that we will get the maximum profit.

Table 4(d)

Number of clusters $=5$

\begin{tabular}{|c|c|c|c|c|c|c|c|c|c|c|}
\hline Locations & $\mathrm{P} 1$ & P3 & P4 & P6 & P8 & P4 & P10 & P3 & P1 & P7 \\
\hline $\begin{array}{l}\text { Total distance of a cus- } \\
\text { tomer from a particular } \\
\text { facility }\end{array}$ & 42.68 & 22.88 & 34.82 & 3.65 & 0 & 18.75 & 12.69 & 10.13 & 56.17 & 28.83 \\
\hline $\begin{array}{l}\text { Total distance between all } \\
\text { customer \& facilities }\end{array}$ & \multicolumn{5}{|c|}{104.03} & \multicolumn{5}{|c|}{126.57} \\
\hline $\begin{array}{l}\text { No. of customers whose } \\
\text { demand was satisfied }\end{array}$ & 17 & 2 & 28 & 2 & 0 & 22 & 9 & 5 & 2 & 12 \\
\hline $\begin{array}{l}\text { Average Customer Dis- } \\
\text { tance from a particular } \\
\text { facility }\end{array}$ & 2.52 & 11.44 & 1.25 & 1.83 & 0 & 0.85 & 1.41 & 2.02 & 28.08 & 2.4 \\
\hline Profit for each cluster & \multirow{2}{*}{\multicolumn{5}{|c|}{77254310}} & 28346710 & 17446510 & 7972330 & 545680 & 20163450 \\
\hline Total Profit & & & & & & \multicolumn{5}{|c|}{74474680} \\
\hline
\end{tabular}

From the Table 3(a to d) \& 4(a to d) we can observe that in case of clustering, when the number of cluster are up to 3 , the total distance travelled by customers is less as compare to without clustering, which results the reduced transportation cost hence the more profit. Now if we further increased the number of clusters the total distance in case of clustering starts increasing, which results the more transportation cost and less profit. Thus from Table 3, for the three clusters we will get the maximum profit Rs8, 42, 35,350 and the minimum distance 73.64 units. Thus we can conclude that, to a certain limit, clustering is useful, which decrease the distance between the facility and the customers and once the profit starts decreasing as we increase the number of clusters it continuously decreases. This is very helpful result which can be used to stop the solution procedure. This is also explained in the Fig. 2 which is plotted for the number of clusters against the profit for example 1 and 2 . The proposed algorithm also provides the number of optimum clusters $=3$ which provides the maximum profit.

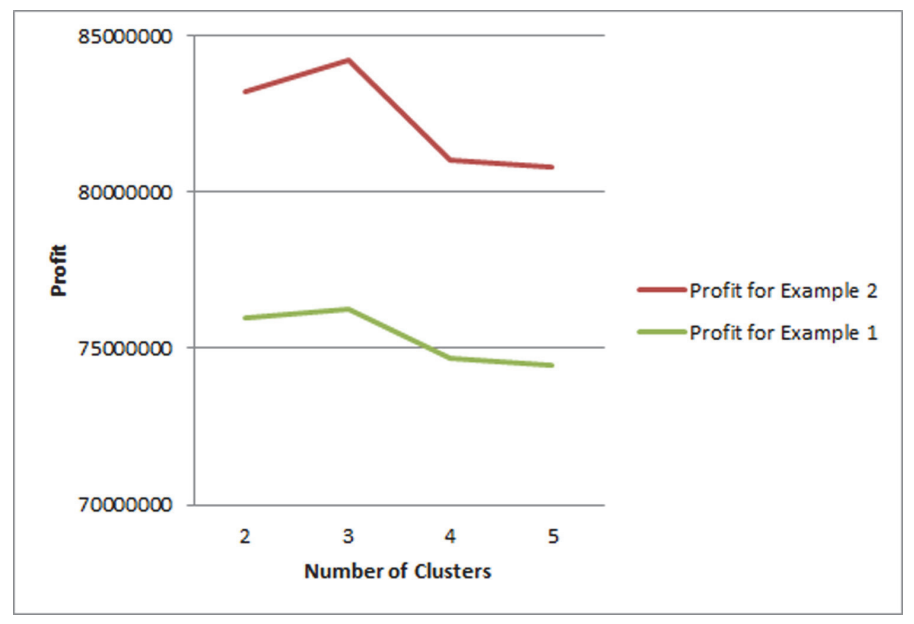

Fig. 2. Number of clusters against the profit for examples 1 and 2

\section{Conclusion}

In this paper, a new clustering and mixed integer linear programming based hybrid approach for FLP is developed. The proposed approach efficiently minimizes the distance between the customer and the facility as well as it also maximizes the profit. This is verified and substantiated by the numerical analysis. With the help of proposed approach the user find whether the clustering is beneficial for him or 
not and if it is beneficial he can also obtain the optimal number of clusters which will maximize the profit. Numerically we proved that once the profit starts decreasing as the number of cluster increases, it continuously decreases this result help us to stop the solution procedure. For the future research, the practitioners can extend the model for more complex and realistic situations, like consideration of random distance.

\section{References}

Arabani, A. B., \& Farahani, R. Z. (2012). Facility location dynamics: An overview of classifications and applications. Computers \& Industrial Engineering, 62(1), 408-420.

Arya, V., Garg, N., Khandekar, R., Meyerson, A., Munagala, K., \& Pandit, V. (2004). Local search heuristics for k-median and facility location problems. SIAM Journal on computing, 33(3), 544-562.

Chaves, A. A., \& Lorena, L. A. N. (2010). Clustering search algorithm for the capacitated centered clustering problem. Computers \& Operations Research, 37(3), 552-558.

Farahani, R. Z., SteadieSeifi, M., \& Asgari, N. (2010). Multiple criteria facility location problems: A survey. Applied Mathematical Modelling, 34(7), 1689-1709.

Farahani, R. Z., Hekmatfar, M., Fahimnia, B., \& Kazemzadeh, N. (2014). Hierarchical facility location problem: Models, classifications, techniques, and applications. Computers \& Industrial Engineering, 68, 104-117.

Geetha, S., Poonthalir, G., \& Vanathi, P. T. (2009). Improved k-means algorithm for capacitated clustering problem. INFOCOMP Journal of Computer Science, 8(4), 52-59.

Kaya, O., \& Urek, B. (2016). A mixed integer nonlinear programming model and heuristic solutions for location, inventory and pricing decisions in a closed loop supply chain. Computers \& Operations Research, 65, 93-103.

Kolisch, R., \& Dahlmann, A. (2015). The dynamic replica placement problem with service levels in content delivery networks: a model and a simulated annealing heuristic. OR spectrum, 37(1), 217242.

Liao, K., \& Guo, D. (2008). A Clustering-Based Approach to the Capacitated Facility Location Problem. Transactions in GIS, 12(3), 323-339.

Lin, P. C., Watada, J., \& Wu, B. (2014). A parametric assessment approach to solving facility-location problems with fuzzy demands. IEEJ Transactions on Electrical and Electronic Engineering, 9(5), 484-493.

Meira, L. A., \& Miyazawa, F. K. (2008, March). A continuous facility location problem and its application to a clustering problem. In Proceedings of the 2008 ACM symposium on Applied computing (pp. 1826-1831). ACM.

Wen, M., \& Iwamura, K. (2008). Facility location-allocation problem in random fuzzy environment: Using $(\alpha, \beta)$-cost minimization model under the Hurewicz criterion. Computers \& Mathematics with Applications, 55(4), 704-713.

Sahraeian, R., \& Kaveh, P. (2010). Solving Capacitated P-Median Problem by Hybrid K-Means Clustering and Fixed Neighborhood Search algorithm. In Proceedings of the 2010 International Conference on Industrial Engineering and Operation Management, 1-6.

Saiedy, H., Moezi, D. S., \& Noruzi, M. (2011). Modeling of capacitated of single allocation hub location problems with n hub centre, Journal of Scientific and Industrial Research, 70 (1) 20-24.

Shishebori, D., \& Ghaderi, A. (2015). An integrated approach for reliable facility location/network design problem with link disruption. International Journal of Supply and Operations Management, 2(1), 640-661.

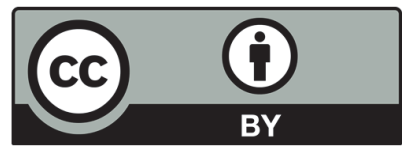

(C) 2017 by the authors; licensee Growing Science, Canada. This is an open access article distributed under the terms and conditions of the Creative Commons Attribution (CC-BY) license (http://creativecommons.org/licenses/by/4.0/). 